\title{
Water quality assessment by combining impedance spectroscopy measurement with cyclic voltammetry
}

\author{
Roman Gruden ${ }^{1}$, Olfa Kanoun ${ }^{2}$ \\ ${ }^{1}$ Seuffer GmbH \& Co. KG, Bärental 26, 75365 Calw, Germany \\ roman.gruden@seuffer.de \\ ${ }^{2}$ Technische Universität Chemnitz, Proffessur für Mess- und Sensortechnik, Reichenhainer Strasse \\ 70, 09126 Chemnitz, Germany \\ olfa.kanoun@etit.tu-chemnitz.de
}

\begin{abstract}
Summary
Optimum detergent dosage during a washing process depends on water quality, degree of pollution and quantity of laundry. Particularly, water quality is an important factor. Other parameters like carbonate- or non-carbonate hardness and calcium-magnesium ratio in addition to total hardness of water have an impact on the amount of detergent.

This work discusses the possibilities to realize a detergent sensor which measures important parameters for the washing process and assess the ideal necessary amount of detergent during the washing process. We propose to combine impedance spectroscopy with cyclic voltammetry in order to determine both water quality and concentration of detergent in the suds which build up the basis for an optimum detergent dosage. The results of cyclic voltammetry show that it is possible to identify the calcium-magnesium ratio and the carbonate hardness separately, which is necessary for the optimization of the washing process. Impedance measurements identify total hardness and detergent concentrations.
\end{abstract}

\section{Introduction}

More than 580,000 tons of detergent and more than one billion liters of water were used in 2010 in Germany for doing the laundry. On average, 30\% of the detergent is superfluous, resulting in water wasting during the rinsing process with impact on environmental burden [1]. Due to the higher concentration of detergent in the suds more and longer rinsing processes will be required to get rid of the detergent residues in the laundry. This requires not only higher water consumption, but also requires more energy. If the rinsing process will not be adapted to the higher detergent concentration, the remaining residues can cause allergic reactions in sensitive individuals. Even the washing result is only at one detergent quantity, customized to the individual properties of this load, optimal [2-4].

Nowadays automatic washing machines use only a control strategy which does not take care of the water quality or the real state of laundry [2-4]. Moving to a regulation strategy by maintaining the washing result needs key parameters such as water quality, quantity of laundry (weight), concentration of dirt and concentration of detergent to be able to compute an optimal dosage. These parameters should be measured online during the washing process with a robust low cost sensor [5], in order to save resources, protect environment and avoid allergic reactions [6].

\section{State of the Art and New Approach}

Optical methods such as turbidity sensors are nowadays used for automatic detergent dosage [7], but they are sensitive to contamination and especially to water dirtiness.

Base-acid titration is able to determine precisely the value of total hardness and the calcium-magnesium ratio [8] but this method is very expensive and works only under laboratory conditions. Voltammetric methods combined with ion-selective electrodes are expensive [9] and not suitable for detergent determination because of complex and different detergent composition [2]. Low-cost applications need environmental harmful mercury electrodes to determine the water parameters [10]. Both methods are not feasible inside the washing machine during the washing process. Electronic tongues are sensor arrays 
combined with voltammetric methods and multivariable analysis [11 - 12] which are tested for white good application [13-15]. The existent problem is the complex data analysis.

To have information about total hardness, conductive methods are more suitable, but they are generally not sufficiently accurate because the conductivity of the electrolyte $\chi_{E}$ depends on the total ion concentration including even ions which are not interesting for the washing process. Moreover $\chi_{E}$ is frequency-dependent and the results of the established methods which use only one frequency is incorrect.

Impedance spectroscopy (EIS) and cyclic voltammetry (CV) are well known analytical methods [16 - 17] and deliver more specific information. For analysis of suds during the washing process they have been not yet applied.

\section{Experimental}

The experimental set-up for electrochemical impedance spectroscopy (EIS) and the cyclic voltammetry $(\mathrm{CV})$ consisted of a Zahner Zennium impedance analyser for frequency range $0.1 \mathrm{~Hz}$ to $4 \mathrm{MHz}$ and an Agilent 9294A impedance analyser (used for EIS only) with measurement adapter Agilent $16048 \mathrm{H}$ for frequency range $40 \mathrm{~Hz}$ to $110 \mathrm{MHz}$. All tests were carried out with a homemade sensor element in a double-walled integral exchanger reactor. The temperature control was a Julabo LH46 Presto. High purity water prepared with a Siemens LaboStar UV7 immediately before the experimental procedure was the basis of all applied solutions. The synthetic water samples were manufactured according to IEC 60734:2003 [18] and the homemade "Seuffer-Verfahren". The reference measurement of each water sample was carried out with the titrator TA20plus and the software TitriSoft 2.6 from SI-Analytics. Reference detergent IEC A / IEC 60456 [19] of Co. wfk - Testgewebe were used for the suds. The water samples for the experiments with different values of carbonate hardness (see Tab. 1) are equal except of the hydrogen carbonate-chloride-ratio $\left(\mathrm{c}\left(\mathrm{HCO}_{3}^{-}+\mathrm{Cl}^{-}\right)=2.56 \mathrm{mmol} / \mathrm{L}=\right.$ const. $)$. All these samples have total ion concentration of $c_{\text {ion }}=4.2 \mathrm{mmol} / \mathrm{L}$.

Tab.1: List of water samples with a total hardness of $1.48 \mathrm{mmol} / \mathrm{L}\left(8.31^{\circ} \mathrm{dH}\right)$ and different carbonate hardness caused by different $\mathrm{HCO}_{3}{ }^{-} \mathrm{Cl}$-ratio

\begin{tabular}{|c|c|c|}
\hline Carbonate Hardness & $\mathrm{HCO}_{3}{ }^{-}-\mathrm{Cl}^{-}$-ratio & Conductivity $\chi_{\mathrm{E}}(\mu \mathrm{S} / \mathrm{cm})$ \\
\hline $0{ }^{\circ} \mathrm{dH}$ & $\mathrm{Cl}^{-}$only & 411.5 \\
\hline $1.4^{\circ} \mathrm{dH}$ & $1: 1.35$ & 392.7 \\
\hline $2.8^{\circ} \mathrm{dH}$ & $1: 0.63$ & 374.3 \\
\hline $3.9^{\circ} \mathrm{dH}$ & $1: 0.25$ & 347.4 \\
\hline $5.2{ }^{\circ} \mathrm{dH}$ & $\mathrm{HCO}_{3}{ }^{-}$only & 337.8 \\
\hline
\end{tabular}

\section{Results and Discussion}

We propose to combine impedance spectroscopy and cyclic voltammetry in order to have a detailed water analysis as a basis for optimal detergent dosage. By means of the impedance spectroscopy, the exact conductivity of the medium can be determined and changes in the composition of the medium can be detected. At the same time, the relative concentration $\alpha_{\text {ion }}$ (eq. (1) and (2)) of the species can be quantified by cyclic voltammetry. Many measurements have been carried out and show the feasibility of the combined measurement principle.

$$
\begin{aligned}
& c_{\text {ion }}=c_{\mathrm{Ca}^{2+}}+c_{\mathrm{Mg}^{2+}}+c_{\mathrm{Na}^{+}}+\ldots+c_{\mathrm{SO}_{4}^{2-}} \\
& 1=\alpha_{\mathrm{Ca}^{2+}}+\alpha_{\mathrm{Mg}^{2+}}+\alpha_{\mathrm{Na}^{+}}+\ldots+\alpha_{\mathrm{SO}_{4}^{2-}}
\end{aligned}
$$

Fig.1a shows the impedance spectra (IS) of water samples with different values of total hardness $(\mathrm{TH})$. The impedance spectra are qualitatively equal because of the identical 
composition of the water samples. The maximum turning point of the impedance spectra equals to the resistance of the electrolyte $R_{\mathrm{E}}$ and is frequency-dependent. The advantage of impedance spectroscopy compared to the usual single frequency conductance measurement is that the maximum turning point, and thus $R_{\mathrm{E}}$, can be precisely determined by the multifrequency method. The conductance $G_{E}$ (reciprocal of $R_{E}$ ) correlates linearly with the total hardness of water (see Fig.1b) with a correlation coefficient of $r=0.9997$. Thereof the resulting sensitivity of $S_{T H}=4.85 \mathrm{mS} \cdot \mathrm{L} / \mathrm{mmol}$ is very good for the planned application. This high correlation is only achievable with synthetic water by use of the precise impedance spectroscopy method and it drops to $r=0.8568$ by measurement of real water. This difference is caused by the different ion concentrations of the ions which do not contribute to total hardness (see Tab. 2, eq. (3) and eq. (4)).

Tab.2: List of the ions which contribute mainly to the total ion concentration of water

\begin{tabular}{|c|c|c|}
\hline Ion & Contribution to & Remarks \\
\hline $\mathrm{Ca}^{2+}$ & Total hardness $(\mathrm{TH})$ & Together with $\mathrm{Mg}^{2+}$ main ion for $\mathrm{TH}$ \\
\hline $\mathrm{Mg}^{2+}$ & Total hardness $(\mathrm{TH})$ & Together with $\mathrm{Ca}^{2+}$ main ion for $\mathrm{TH}$ \\
\hline $\mathrm{Na}^{+}$ & Only total ion concentration (TIC) & - \\
\hline $\mathrm{K}^{+}$ & Only total ion concentration (TIC) & - \\
\hline $\mathrm{HCO}_{3}^{-}$ & Carbonate hardness $(\mathrm{KH})$ & \multirow{3}{*}{$\begin{array}{l}\text { All anions contribute to the } \\
\text { conductivity of the total hardness, } \\
\text { depending on the composition. }\end{array}$} \\
\hline $\mathrm{Cl}^{-}$ & Non carbonate hardness (NKH) & \\
\hline $\mathrm{SO}_{4}^{2-}$ & Non carbonate hardness (NKH) & \\
\hline
\end{tabular}

$$
\begin{gathered}
\chi_{\mathrm{E}}=c_{\mathrm{Ca}^{2+}} \cdot \Lambda_{\mathrm{Ca}^{2+}}^{0}+c_{\mathrm{Mg}^{2+}} \cdot \Lambda_{\mathrm{Mg}^{2+}}^{0}+\ldots+c_{\mathrm{SO}_{4}^{2+}} \cdot \Lambda_{\mathrm{SO}_{4}^{2+}}^{0} \\
\bar{\chi}_{\mathrm{TH}}=\bar{\chi}_{\mathrm{E}}-\chi_{\varepsilon} \rightarrow \bar{\chi}_{\mathrm{TH}} \approx \bar{\chi}_{\mathrm{E}}
\end{gathered}
$$

The relationship between conductance $G_{E}$ and conductivity $\chi_{E}$ is given by the cell constant $K$ of the sensor element.

$$
\chi_{\mathrm{E}}=G_{\mathrm{E}} \cdot K
$$

The conductivity $\chi_{\mathrm{E}}$ of the water sample is composed of the concentration of each species $c_{S P}$ multiplied by its molar limit conductivity $\Lambda^{0}$. The portion of conductivity which represents the total hardness of water $\chi_{\mathrm{TH}}$ cannot be clearly defined because of the different combination possibilities of the hardness forming cations $\mathrm{Ca}^{2+}$ and $\mathrm{Mg}^{2+}$ with its possible corresponding anions $\mathrm{HCO}_{3}^{-}, \mathrm{Cl}^{-}$and $\mathrm{SO}_{4}^{2-}$. All combinations between the cations and anions are possible and lead to different conductivities which do not correlate to the chemical effects. The arithmetic mean of $\chi_{\mathrm{TH}}$ equals to $\chi_{\mathrm{E}}$ if the fault $\chi_{\varepsilon}$ is low or the requirements to the results are not strict. This results in the need for a differentiated analysis of ions in case of precise measurement requirements. 


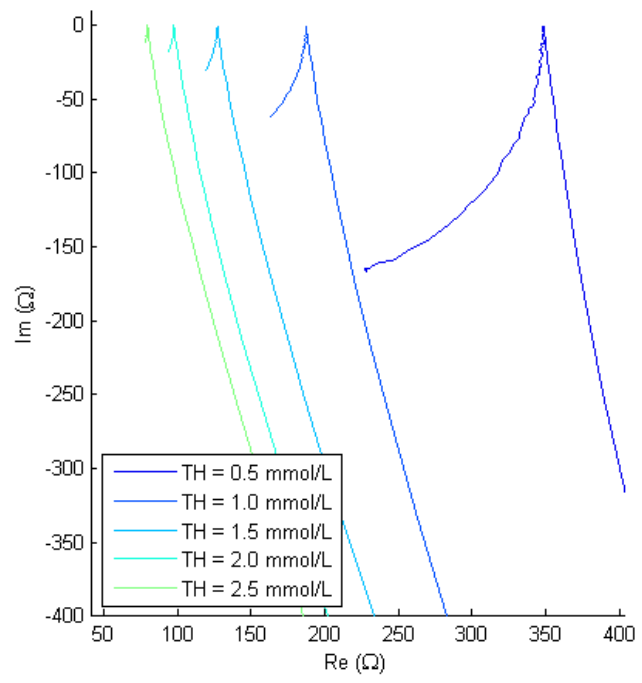

Fig.1a: Dependence of the IS on total hardness.

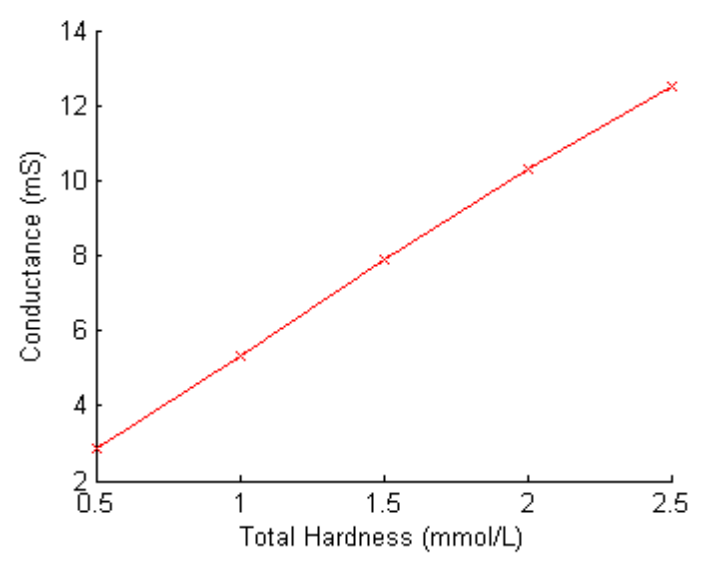

Fig.1b: Dependence of the conductance on $\mathrm{TH}$.

Fig.2a shows the impedance spectra of suds with different concentrations $c_{\text {det }}$. The maximum turning points correlate strongly with the concentration of the suds $(r \approx 1)$ as long as they do not exceed a certain value (see Fig.2b). Above this concentration $c_{\mathrm{cmc}}$, the conductivity increases again linearly with the concentration, but with a lesser gradient. Thus there are two lines and their intersection point marks the critical micelle concentration $(\mathrm{cmc})$ [20 - 22]. There is a strong presumption that the optimum detergent concentration is close to the critical micelle concentration. On this issue intensive tests are carried out currently.

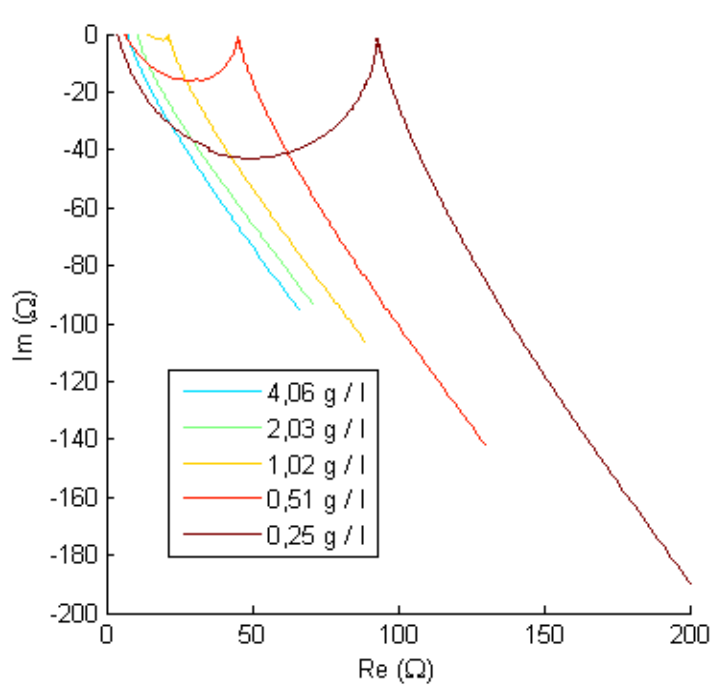

Fig.2a: Dependence of the IS on detergent concentration.

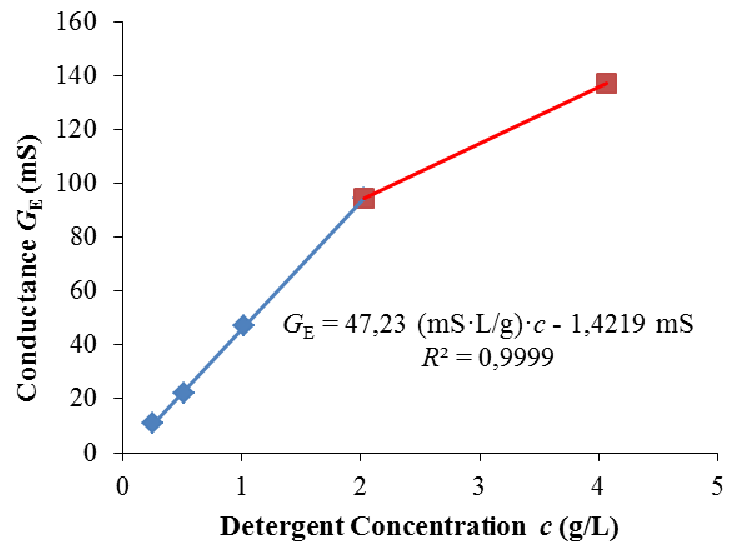

Fig.2b: Dependence of the conductance on detergent concentration.

Fig.3a shows the impedance spectra of five water samples, all of them has a total hardness of $1.48 \mathrm{mmol} / \mathrm{L}\left(8.31^{\circ} \mathrm{dH}\right)$ but different carbonate hardness values (see Tab. 1). All spectra are qualitatively equal. To distinguish them from the spectra of different total hardness values, further information by an additional measurement principle is necessary. Fig.3b shows the results of the water investigation by cyclic voltammetry. A sensitivity of $S_{i}=-6.7 \mu \mathrm{A} \cdot \mathrm{L} / \mathrm{mmol}$ was reached, which is sufficient for the target application. The absolute value of current $I$ decreases linearly with the increasing carbonate hardness. The reason is that the ratio of the anions changes. The concentration of $\mathrm{HCO}_{3}{ }^{-}$increases and the concentration of $\mathrm{Cl}^{-}$ions decrease. $\mathrm{Cl}^{-}$ions have a higher contribution to the conductivity than $\mathrm{HCO}_{3}{ }^{-}$. 


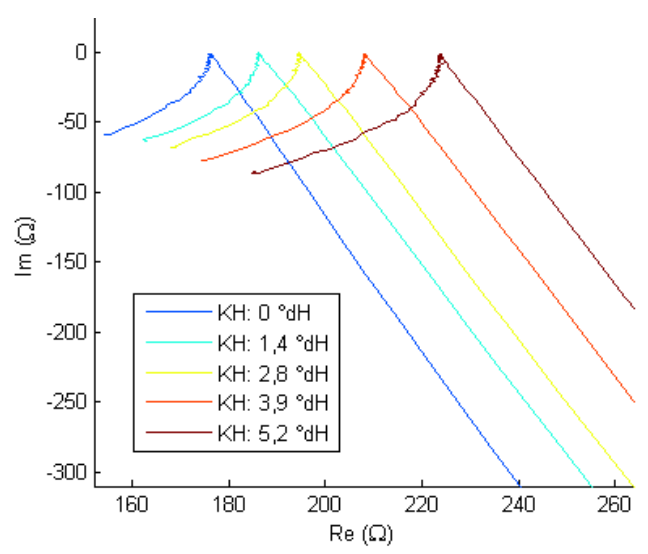

Fig.3a: Impedance spectra of water samples with the same total hardness and different carbonate hardness.

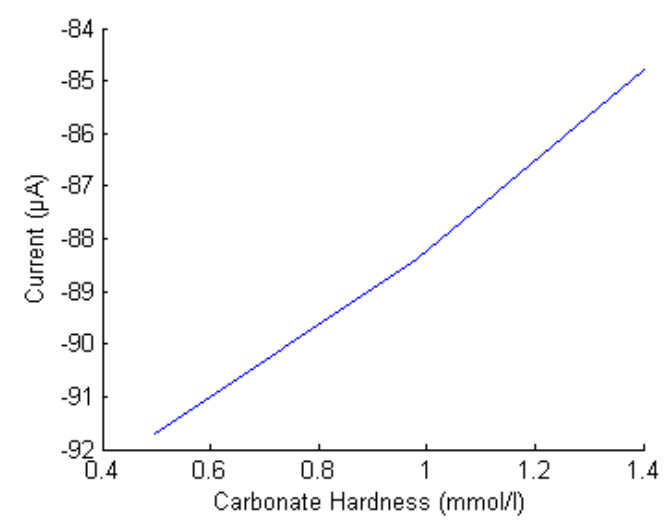

Fig.3b: Current response as a function of carbonate hardness.

Fig.4a shows the impedance spectra of water samples with identical total and carbonate hardness but with a different calcium-magnesium ratio. The impedance spectra are qualitatively and quantitatively identical and thus it is not possible to distinguish different calcium-magnesium ratios by impedance spectroscopy. The water samples are nearly identical from electrochemical point of view because the earth alkaline metals calcium and magnesium behave very similar. Fig.4b shows the result of an investigation of the water samples by cyclic voltammetry. A correlation of the relaxation time and the calciummagnesium ratio can be clearly seen. The relaxation time depends on the ionic radii of the species. Different radii mean different speeds of the ions.

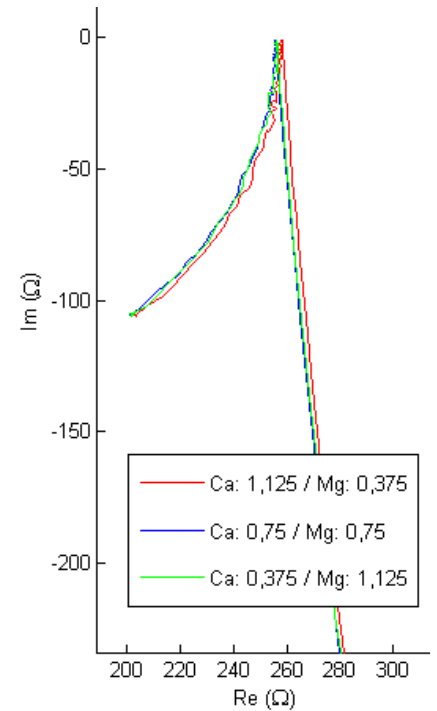

Fig.4a: Impedance spectra of water samples with the same total and carbonate hardness but different calcium-magnesium ratio ( $\mathrm{mmol} / \mathrm{L})$.

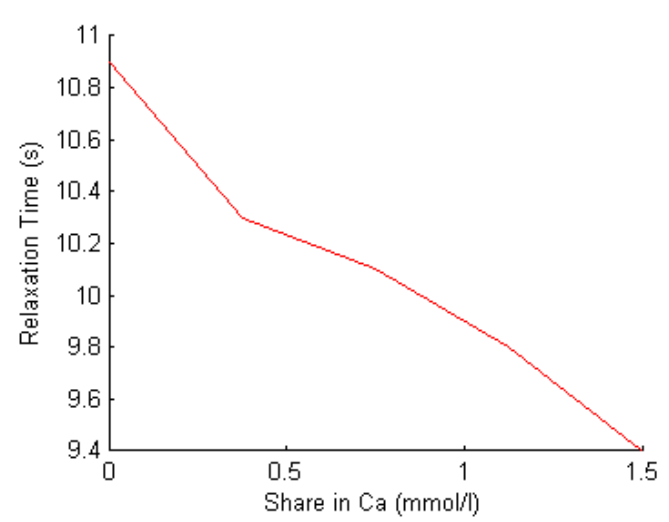

Fig.4b: Relaxation time depending on calcium-magnesium ratio. 


\section{Conclusion}

The results show that it is possible to determine the detergent concentration of suds and the parameters of water which has impact on the washing process by a combination of impedance spectroscopy (EIS) and cyclic voltammetry (CV). A big advantage of impedance spectroscopy as a multi-frequency method in comparison to conventional conductance measuring methods is the possibility to determine $R_{\mathrm{E}}$ precisely and thus form a solid basis for all further investigations. Moreover, the results showed that additional information like the angle of the diffusion line can be obtained from the impedance spectra to characterize the water composition more detailed. Such investigations are in progress and necessary to improve the planned application.

The detergent concentration of the suds can be measured precisely by impedance spectroscopy as well. The implementation of this method for the cmc-detection and thus the optimization of the detergent amount and the washing process is in progress.

To determine the carbonate hardness and the calcium-magnesium ratio, a combination of the results of impedance spectroscopy and cyclic voltammetry is necessary and the results show the feasibility. Both methods can be realized with the same sensor element and the same hardware.

The planned application can be realized as a low cost solution for an online measurement during the washing process without environmental harmful substances. The realized measurements indicate the feasibility of the planned application. For a final version some points like the online detection of the critical micelle concentration and the precise correlation of the measurement data to the water parameters has still to be clarified. Such tests are in progress.

\section{References}

[1] I. Rüdenauer, C.-O. Gensch, Einsparpotentiale durch automatische Dosierung bei Waschmaschinen, ÖkoInstitut e.V., Studie im Auftrag der Miele \& Cie. KG, 2008

[2] G. Wagner, Waschmittel, Viley VCH, 2010

[3] E. Smulders, W. Rähse, W. von Rybinski, J. Steber, E. Sung, F. Wiebel, Laundry Dertergents, Wil, 2002

[4] G. Jakobi, A. Löhr, Detergents and Textile Washing, VCH, 1987

[5] R. Gruden, O. Kanoun, U. Tröltzsch, Influence of surface effects on the characterisic curves of detergent sensors, $9^{\text {th }}$ International Multi-Conference on Signals, Sensors and Devices, Chemnitz: 20.-23. März 2012

[6] U. Tröltzsch, R. Gruden, O. Kanoun, A. Buchholz, V. Beck, Anwendungspotential der Impedanzspektroskopie für die Waschlaugensensorik, 16. GMA/ITG-Fachtagung Sensoren und Messsysteme, 650 - 661 (2012) ; doi: 10.5162/sensoren2012/6.2.4

[7] G. Czyzewski, I. Schulze, C. Engel, Europäische Patentanmeldung EP 0992622 A2, 1999

[8] L. A. Hütter, Wasser und Wasseruntersuchung, Otto Salle Verlag und Verlag Sauerländer, 1990

[9] K. Cammann, H. Galster, Das Arbeiten mit ionenselektiven Elektroden, Springer Verlag, 1996

[10] E. Pungor, G. Nagy, Z. Feher, The flat surfaced membrane coated mercury electrode as analytical tool in the continuous voltammetric analysis, Journal of Electroanalytical Chemistry 75, $241-254$ (1977)

[11] F. Winquist, Microchimica Acta 163, 3 - 10 (2008); doi: 10.1007/s00604-007-0929-2

[12] F. Winquist, P. Wide, I. Lundström, An electronic tongue based on voltammetry, Analytica Chimica Acta 357, $21-31(1997)$

[13] F. Winquist, J. Olsson, M. Eriksson, Analytica Chimica Acta 683, 192 - 197 (2011); doi: 10.1016/j.aca.2010.10.027

[14] P. Ivarsson, Electronic Tongues - New Sensor Technology in Household Appliances, Linköping, Sweden (2003)

[15] M. Eriksson et. al., Procedia Engineering 25, 1165 - 1168 (2011); doi: 10.1016/j.proeng.2011.12.287

[16] E. Barsoukov \& J. R. Macdonald, Impedance Spectroscopy, WILEY-INTERSCIENCE (2005)

[17] A. J. Brad \& L. R. Faulkner, Electrochemical Methods, John Wiley \& Sons (2001)

[18] Household electrical applicances Performance - Hard water for testing (IEC 60734:2003), CENELEC (European Committee for Electrotechnical Standardization), Brüssel (2003)

[19] IEC A* Referenzwaschmittel nach IEC 60456 Order Code: 88010-1, WFK IEC A*, wfk-Testgewebe GmbH, Brüggen-Bracht

[20] H. Nakamura, A. Sano, K. Matsuura, Determination of Critical Micelle Concentration of Anionic Surfactants by Capillary Electrophoresis Using 2-Naphthalenemethanol as a Marker for Micelle Formation, Journal of Analytical Sciences 14, $379-382(1998)$

[21] J. M. G. Neto,H. N. da Cunha, J. M. M. Neto, G. F. L. Ferreira, Impedance spectroscopy analysis in a complex system: Sodium dodecyl sulfate solutions, Journal of Sol-Gel Science and Technology 38, $191-195$ (2006)

[22] H.-C. Chang, B.-J. Hwang, Y.-Y. Lin, L.-J. Chen, S.-Y. Lin, Measurement of critical micelle concentration of nonionic surfactant solutions using impedance spectroscopy technique, Review of Scientific Instruments 69, $2514-2520$ (1998) 